\title{
Neonatal intensive care unit lighting: update and recommendations
}

\author{
Roberto G. Rodríguez Ph.D. ${ }^{a}$ and Andrea E. Pattini Ph.D. ${ }^{a}$
}

\begin{abstract}
Achieving adequate lighting in neonatal intensive care units is a major challenge: in addition to the usual considerations of visual performance, cost, energy and aesthetics, there appear different biological needs of patients, health care providers and family members. Communicational aspects of light, its role as a facilitator of the visual function of doctors and nurses, and its effects on the newborn infant physiology and development were addressed in order to review the effects of light (natural and artificial) within neonatal care with a focus on development. The role of light in regulating the newborn infant circadian cycle in particular and the therapeutic use of light in general were also reviewed. For each aspect, practical recommendations were specified for a proper well-lit environment in neonatal intensive care units.

Key words: review, intensive care, lighting, ergonomics
\end{abstract}

http:/ /dx.doi.org/10.5546/aap.2016.eng.361

\section{INTRODUCTION}

Continuous advances in neonatology have increased the chances of survival of preterm and critically ill newborn infants. Although neonatal intensive care units (NICU) provide highly specialized medical care, they do not necessarily offer an ideal environment for the development of newborn infants. There is a huge difference between intrauterine environment and the NICU environment. ${ }^{1}$ The former is an econiche that offers maternal protection, continuous nutrient supply, stable temperature and chronobiological cycles, while the latter is characterized by an inappropriate, non-contingent, nonreciprocal and painful stimulation pattern in a moment of major structural and functional brain development. This transition to extrauterine life imposes even greater demands, due to the physiological limitations of inpatients and their restricted ability to adapt to the environment and reject unwanted stimuli. The physical environment (light, temperature, sound, radiations) in the NICU is a critical issue, which can affect the normal development of a newborn infant. ${ }^{2}$ The interactive development theory indicates that the newborn baby actively responds to the environment looking for balance. These dynamics offer beneficial opportunities for preventive and therapeutic interventions. ${ }^{3,4}$

Once the newborn infant's individuality is recognized, Sparshott ${ }^{5}$ categorizes many features of the neonatal unit environment: safety, comfort, right posture, proper development, communication, rest and sleep, dignified death. These principles correspond to an approach to medical care, which combine technological and human features: development-centered care to meet the newborns and their family's needs.

Argentina has initiatives, handbooks and guidelines for the implementation of this paradigm of care. ${ }^{6}$ It also has a law regulating parents' and children's right during the process of birth (Law 25929) and a Regulation on the Organization and Operation of Neonatology Services and Neonatal Intensive Care (Res. 306/2002), which includes physical environment and its lighting. However, there is no legal and regulatory framework specifying the proper lighting parameters in a NICU.

The aim of this article is to review the effects of lighting in newborn infants and provide recommendations for proper lighting within the development-centered care. Methodological aspects of this review may be referred to in the Annex attached to this publication. 


\section{LIGHT ENVIRONMENT IN A NEONATAL INTENSIVE CARE UNIT}

Both artificial and natural lighting play several roles in the NICU environment: it communicates and conveys sensations, supports the visual function of doctors and nurses, affects the newborn infant's physiology and development, and regulates the circadian function, in addition to its therapeutic use. $^{7-10}$

\section{Communicational aspects of lighting}

A safe and family-centered NICU must be considered the newborn infant's "first home". It should have a cozy atmosphere, caring for patients and family members' comfort. ${ }^{11,12}$ The interior decoration and the careful environment design may turn a high technology clinical area in a more enjoyable place for newborn infants and family members. ${ }^{9,13,14}$

Evidence suggests that natural light (NL) and contact with nature deeply influence human health and welfare. ${ }^{15}$ In the clinical field, more studies dealing with the possible positive effects of lighting on health have been conducted compared to the positive effects of natural landscapes seen from inside. ${ }^{15}$ In addition, the use of NL systems and strategies helps reduce power consumption and improves interior space quality of use..$^{16-20}$

To maximize these benefits, NL contribution should be carefully planned, as there are problems associated with uncontrolled sunlight's entrance: it interferes visual performance (glaring, screen reflections, spots of light), it affects visual and thermal comfort, and has unwanted radiation (infrared, ultraviolet).

\section{Recommendations:}

- Generate points of interest, either by contrast or by color, emphasizing, through lighting, desirable stimuli such as photographs or artistic images. ${ }^{20}$

- Achieve a flexible lighting system, which is adjustable either individually or by areas within the Unit so as to meet the varied needs of newborn infants who share the NICU.

- Incorporate NL in the hospitalization area and locate cribs more than $60 \mathrm{~cm}$ away from windows. Sealed double glazed is preferable so as to minimize heat loss.

- Include external elements of solar control (sunshades, eaves, louvers) in windows, which are easy to maintain and clean, and which allow flexible use as needed. Use neutral colors to minimize color distortion. ${ }^{21}$

- Avoid direct sunlight radiation both on patients and on IV fluids and data display screens. Avoid glare on doctors' and nurses' eyes. ${ }^{21}$

\section{Light as visual function support of doctors and nurses}

Lighting level (measured in lux) in neonatal units has described a parabolic curve since the second half of the twentieth century. ${ }^{22}$ NICUs from the 80s were bright and well-lit, matching technological burst and the highly sophisticated neonatal care.

Nowadays, there is a trend to use lower lighting levels. With the use of current monitoring systems, the need for direct observation has decreased, so it is not necessary to use intense light to monitor newborn infants. ${ }^{23}$ It is generally agreed that newborn infants are more stable and consume less energy in low light conditions, which are also necessary for procedures such as echocardiograms or transillumination. ${ }^{24}$

Moreover, in a NICU, speed and mainly accuracy are essential for tasks performance. Higher levels of lighting allow greater visual acuity, and improve signal-noise ratio for visual tasks and visual functions speed. ${ }^{7}$ A good perception of color is crucial for the clinical examination of patients. ${ }^{25}$ The color rendering index (CRI) allows to determine color rendering properties of a light source. Taking as a standard the NL $(C R I=100)$, this index measures how "natural" colors are perceived when illuminated by an artificial light source.

\section{Recommendations:}

- Examine the infant, the color of their skin and mucous membranes, and their perfusion anywhere in the room, with a range of general illumination of 10-600 lux. ${ }^{26}$

- Use individualized light sources of, at least, 2000 lux to examine the newborn infant or to perform specific procedures in short periods avoiding the exposure of nearby patients. ${ }^{24}$

- Avoid reflections on screens by diffuse general lighting so as not to hinder the reading of important visual information, either on monitoring screen or during diagnostic procedures.

- Interior surfaces (walls, floor, ceiling) should be clear with a matt finish so that the interior light is distributed diffusely to avoid glare. ${ }^{9,13}$

- Sources of artificial lighting must have a CRI 
greater than $80 .{ }^{21}$ Their optical reflectors must have a natural finish to maintain the properties of color rendering.

\section{Effects of light on the newborn infant physiology and development}

The newborn infant visual system is not fully developed at birth, and over the last trimester of pregnancy, major developments of the nervous and visual systems occur, continuing their structural and functional maturation during childhood. ${ }^{27}$ Lighting influences postnatal development of vision and visual processes and the maturation of the visual cortex, which is affected by premature visual experiences. ${ }^{8,24,28,29}$ Factors that regulate the amount of light reaching infants' eyes are biological: eyelid opening, transmission through them, pupil diameter (starting at 30-34 weeks old after birth) and transmission features of the ocular media. ${ }^{30}$ Until full-term gestational age, light is not necessary for visual development, and it does not seem appropriate to subject the preterm infant to intense light when this does not occur in utero. ${ }^{31}$

Evidence indicates that exposure to very bright light can harm the immature eye. ${ }^{32}$ High lighting levels have been associated with adverse clinical outcomes: less weight gain, behavioral and sleep disturbances, in addition to stress in very preterm or seriously ill patients. ${ }^{7,24,33-35}$ A sudden change in the amount of light also affects the newborn infant: Shogan and Schumann ${ }^{36}$ reported rapid saturation declines in preterm infants after a sudden increase in lighting. Preterm newborn infants are visually more vulnerable: they get tired easily, have very thin eyelids and their immaturity prevents them from closing their eyes consistently, so they have limited resources for protection from light. ${ }^{37,38}$ Changes in ambient lighting include temporary effects: a reduced level of lighting produces an immediate and transient opening of the eyelids, followed by a significantly longer period when this dimmer illumination is kept. It has been published that effects of light reduction in the NICU include a better stability of the newborn infant, respiratory stability, decreased heart rate and respiratory rate, blood pressure and motor activity, shorter time in ventilation and oxygen support. ${ }^{30}$

\section{Recommendations:}

- Limit visual stimulation that competes with auditory and tactile information prevailing in a NICU to avoid sensory interference during this stage of development.
- Avoid direct light to the newborn infant's eyes at all times.

- Use progressive lighting to enable a gradual dark-light shift to reduce the stress produced in the newborn infant by a sudden change in ambient lighting.

\section{Light as a regulator of the circadian cycle of the newborn infant}

Rivkees ${ }^{39}$ notes that, although fetus development takes place in the dark, this environment is rich in auditory, tactile and kinesthetic sensory stimulation. Keeping preterm patients in a continuously dark environment while in the NICU, deprives them of the circadian stimuli they would have received during gestation. ${ }^{40}$

The fetal biological clock is an endogenous system that generates circadian rhythms in response to maternal signals (activity, heart rate, cortisol, melatonin, body temperature), at least from the third quarter of gestation.

As the light entering the retina is the main external regulator of the human circadian system, in 1997, the American Academy of Pediatrics suggested introducing regular cycles of day-night lighting in the NICU. ${ }^{41,42}$ This is to preserve life and provide proper medical care in a uterus-like environment, thus continuing as much as possible, the experience that has been interrupted at an early stage.

Research supports the importance of circadian rhythms for the fetus and the relative lack of them in preterm infants. ${ }^{39,40,42-44}$ Evidence indicates that, between weeks 28 and 32 of gestation, cyclical lighting has positive clinical effects on the newborn infant, but there is little information on the effect of circadian rhythm on physiological functions, growth and development of the central nervous system. ${ }^{40,42,45-50}$ There is still no consensus on how to introduce circadian cycles with artificial lighting in practice neither is there an implementation protocol regarding cycle length and maximum/minimum lighting levels. ${ }^{50}$

\section{Recommendations:}

- Implement a cyclic lighting schedule. During the day, between 100 and 200 lux, with some natural light. At night, artificial light lower than 50 lux, with a NL-like spectral distribution.

- Day/night lighting should be capable of increases up to 600 lux with independent control for separate lights. ${ }^{51}$ 
- The use of individual blankets is an alternative, and a higher mean duration of non-REM (rapid eye movement) periods has been reported in stable preterm infants protected by blankets. ${ }^{52}$

\section{Therapeutic use of light}

Neonatal jaundice is the most common disorder among newborn infants. It is estimated that $60 \%-70 \%$ of newborn infants have jaundice. ${ }^{53}$ It is a benign and self-limited condition that normally goes away before the age of one month. ${ }^{54}$ However, the serum unconjugated bilirubin level should be monitored to avoid toxic levels to the central nervous system. Phototherapy maintains or lowers blood bilirubin levels through photolysis. The newborn infant's skin is exposed to light and their eyes are usually protected. However, newborn infants in neighboring cribs do not always have their eyes covered, and even infants under treatment sometimes remove their eye protection. ${ }^{7}$ To counteract this, the optical fiber blankets wrapping newborn infants are an already published alternative. ${ }^{55}$

With a less dense macular pigment and ocular media that transmits more short wavelength (blue) and ultraviolet energy, the newborn infant has a higher risk of eye damage by shortwave light, among many other susceptibilities associated with the developing visual system. ${ }^{56}$ With a peak sensitivity of $440 \mathrm{~nm}$, exposure to this area of electromagnetic spectrum could cause oxidative damage to photoreceptors and prevent normal regeneration process. This process was described on in vitro studies and animal models. ${ }^{57-59}$ Both the human circadian system and bilirubin photolysis require shortwave light. These processes have their greatest spectral sensitivity at $450 \mathrm{~nm}$, area adjacent to peak of 440 $\mathrm{nm}$ of blue light damage function. 8,60

Retinopathy of prematurity (ROP) is a major cause of blindness. Babies born with less than $1500 \mathrm{~g}$ and/or less than 32 weeks of gestational age are at an increased risk. This group should be monitored through serial ophthalmologic exams until complete retinal maturation is accomplished. When the disease was first described, it was suggested that early exposure of the retina to light could increase the number of free radicals, which contributes to ROP development. ${ }^{61}$ Since the fifties of the twentieth century, excessive use of oxygen has been known to increase the risk of ROP. ${ }^{62}$ Animal studies showed injury to the retina after exposure to extremely bright lights for long periods, something that is not usually practiced in a NICU. 10,33,63,64

Interest in lighting was revived after the work by Glass and his colleagues, ${ }^{65}$ who reported a ROP incidence reduction by lowering lighting in the NICU. Searching for a definitive answer about the effect of light on ROP, a multicenter randomized study called LIGHT-ROP was conducted. In this study, no significant differences were found in the severity of ROP among newborn infants exposed and unexposed to light. ${ }^{66}$ While it is generally accepted that light is not a risk factor for ROP development, it is still a controversial issue. ${ }^{67-69}$

According to Fielder and Moseley, ${ }^{30}$ light does not affect ROP development, but its role in the pathogenesis of other ophthalmologic sequelae of preterm birth is unknown.

\section{Recommendations:}

- Lamps in the blue region of the spectrum (460$490 \mathrm{~nm}$ ) are the most effective ones in treating hyperbilirubinemia.

-When using lamps for therapeutic purposes, limit the intensity of light source to the minimum required by the task and minimize exposure time.

- Avoid exposing the newborn infant's eyes to ultraviolet and infrared radiation through the use of appropriate lamps, lenses or filters.

\section{CONCLUSIONS}

Getting proper lighting in a NICU is a huge challenge. Apart from issues related to visual performance, cost, energy and aesthetics, the wide variety of biological needs of patients, health care providers and family members must be addressed.

A growing body of knowledge has been developed around the positive and/or negative effects of environmental factors on newborn infants, grouped in a relatively recent disciplinary field: environmental neonatology. However, there is less availability of guidelines and recommendations for the practical implementation of such scientific knowledge.

This update was based on several sources (legal, empirical, technical, scientific) to describe the current status of the visual environment in a NICU. Far from being comprehensive, this update is intended as a guide to rationally define lighting in hospital admission area without neglecting the patients, family members and providers' complex needs.

Lastly, this paper is thought of as a trigger to formulate, through discussion and consensus, 
a framework of legal and regulatory reference in our own country, according to developmentcentered neonatal care principles. A safe and bright environment that fosters the newborn infant's development requires low-tech and little economic investment (compared to the NICU equipment) but high performance interventions when considering the benefits to newborn infants described herein. $\mathrm{n}$

\section{REFERENCES}

1. Pallas Alonso CR, Gutiérrez Argul O. El ambiente en los cuidados intensivos neonatales. An Esp Pediatr 1997;47(6):618-20.

2. Hunt KN. The NICU: Environmental Effects of the Neonatal Intensive Care Unit on Infants and Caregivers. Research Papers 2011. Paper 71. [Accessed on: January 12, 2016]. Available at: http://opensiuc.lib.siu.edu/cgi/ viewcontent.cgi? article $=1068 \&$ context $=g$ s_rp.

3. Als H. A synactive model of neonatal behavioral organization: framework for the assessment of neurobehavioral development in the premature infant and for support of infants and parents in the neonatal intensive care environment. Phys Occup Ther Pediatr 1986;6(3-4):3-53.

4. Franck LS, Lawhon G. Environmental and behavioral strategies to prevent and manage neonatal pain. Semin Perinatol 1998;22(5):434-43.

5. Sparshott M. Pain, distress and the newborn baby. UK: Wiley-Blackwell; 1996.

6. Larguía AM, González MA, Solana C, Basualdo MN, et al. Maternidad Segura y Centrada en la Familia. (MSCF): Conceptualización e implementación del modelo. Buenos Aires: UNICEF; 2011. [Accessed on: March 01, 2016]. Availableat:http://www.unicef.org/argentina/spanish/ GUIA_MSCF.pdf.

7. Bullough J, Rea MS. Lighting for neonatal intensive care units: some critical information for design. Light Res Technol 1996;28(4):189-98.

8. Rea M. Lighting for caregivers in the neonatal intensive care unit. Clin Prinatol 2004;31(2):229-42.

9. Rizzo P, Rea M, White R. Lighting for today's neonatal intensive care unit. Newborn Infant Nurs Rev 2010;10(2): 107-13.

10. Lai TT, Bearer CF. Jatrogenic environmental hazards in the neonatal intensive care unit. Clin Perinatol 2008;35(1): 163-81.

11. Cooper LG, Gooding JS, Gallagher J, Sternesky L, et al. Impact of a family-centered care initiative on NICU care, staff and families. J Perinatol 2007;27(Suppl 2):S32-7.

12. Laing I, Ducker T, Leaf A, Newmarch P. Designing a Neonatal Unit. Report for the British Association of Perinatal Medicine, 2004. [Accessed on: March 01, 2016]. Available at: http://www.bapm.org/publications/documents / guidelines/DesigningNNU_May2004b.pdf.

13. White RD. Lighting in the neonatal intensive care unit: practical applications of scientific principles. Clin Perinatol 2004;31(2):323-30.14. Dalke H, Little J, Niemann E, Camgoz N, et al. Colour and lighting in hospital design. Opt Laser Technol 2006;38(4-6):343-65.

14. BeuteF, deKortYA. Salutogenic effects of the environment: Review of health protective effects of nature and daylight. Appl Psychol Health Well Being 2014;6(1):67-95.

15. Boyce P, Hunter C, Howlett O. The benefits of Daylight through Windows. Troy, New York: RensselaerPolytechnic Institute, 2003. [Accessed on: March 01, 2016]. Available at: http://thedaylightsite.com/wp-content/uploads / papers/DaylightBenefits.pdf.
16. Leslie R. Capturing the daylight dividend in buildings: why and how? Buil Environ 2003;38(2):381-5.

18. Joseph A. The Impact of Light on Outcomes in Healthcare Settings. Issue Paper 2, 2006. Concord, CA: The Center for Health Design. [Accessed on: January 12, 2016]. Available at: http://www.healthdesign.org/sites/default/files / CHD_Issue_Paper2.pdf.

19. Alzoubi H, Al-Rqaibat S, Bataineh RF. Pre-versus postoccupancy evaluation of daylight quality in hospitals. Buil Environ 2010;45(12):2652-65.

20. Iyendo TO, Alibaba HZ. Enhancing the Hospital Healing Environment through Art and Day-lighting for User's Therapeutic Process. IJAC 2014;3(9):101-19.

21. WhiteRD,SmithJA,ShepleyMM. Recommended standards for newborn ICU design, eighth edition. J Perinatol 2013;33(Suppl 1):S2-16.

22. García Sánchez P. Cuidado neonatal con atención al desarrollo. Rev Esp Ped 2002;58(343):28-36.

23. Young J. The visual system. In Young J, ed. Developmental Care of the Premature Baby. London: Baillieré Tindall; 1996. Pages 21-33.

24. White RD. Recommended standards for the newborn ICU. J Perinatol 2007;27(Suppl 2):S4-19.

25. Figueiro MG, Rea MS, Boyce P, White R, Kolberg K. The effects of bright light on day and night shift nurses' performance and well-being in the NICU. Neonatal Intensive Care 2001;14(1):29-32.

26. DiLaura D, Houser KW, Mistrick RG, Steffy GR (eds). The Lighting Handbook 10th ed: Reference and Application. New York: Illuminating Engineering Society of North America; 2011.Pág.120.

27. Birch EE, O'Connor AR. Preterm birth and visual development. Semin Neonatol 2001;6(6):487-97.

28. Logvinov SV, Potapov AV, Varakuta EY, Drobatulina DA. Dynamics of structural changes in the retina during long-term exposure to bright light. Bull Exp Biol Med 2003;136(4):411-4.

29. Szczepa ski M,Kamianowska M. Theillumination intensity in the neonatal intensive care unit. Arch Perinat Med 2008;14(2):47-50.

30. Fielder AR, Moseley MJ. Environmental Light and the Preterm Infant. Semin Perinatol 2000;24(4):291-8.

31. UK Department of Health. Guidance for the design of hospital neonatal units including special care, family spaces and specialist clinical rooms. Health Building Note 03.09: Neonatal units. 2013. [Accessed on: March 01, 2016]. Availableat:https://www.gov.uk/government/uploads/ system/uploads/attachment_data/file/147879/HBN_0903_Final.pdf.

32. Havelius U, Hansen F, Hindfelt B, Krakau T. Human ocular vasodynamic changes in light and darkness. Invest Ophthalmol Vis Sci 1999;40(8):1850-5.

33. Pickler RH, McGrath JM, Reyna BA, Tubbs-Cooley HL, et al. Effects of the neonatal intensive care unit environment on preterm infant oral feeding. Res Rep Neonatol 2013;2013(3):15-20.

34. SheldonSH, BellE. Light, Sleep, and Development. Pediatrics 1987;79(6):1053-4.

35. Peng N, Bachman H,Jenkins R, Chen $\mathrm{CH}$, etal. Relationships between environmental stressors and stress biobehavioral responses of preterm infants in NICU. J Perinat Neonatal Nurs 2009;23(4):363-71.

36. Shogan MG, Schumann LL. The effect of environmental lighting on the oxygen saturation of preterm infants in the NICU. Neonatal Netw 1993;12(5):7-13.

37. Robinson J, Fielder AR. Pupillary diameter and reaction to light in preterm neonates. Arch Dis Child 1990;65(1 Spec No):35-8. 
38. Robinson J, Fielder AR. Light and the immature visual system. Eye (Lond) 1992;6(Pt 2):166-72.

39. Rivkees SA. Developing circadian rhythmicity in infants. Pediatrics 2003;112(2):373-81.

40. Rivkees SA. Emergence and influences of circadian rhythmicity in infants. Clin Perinatol 2004;31(2):217-28.

41. Moore-Ede MC, Sulzman FM, Fuller CA. The Clocks That Time Us: Physiology of the Circadian Timing System. Cambridge, MA: Harvard University Press; 1982.

42. Mirmiran M, Ariagno RL. Influence of light in the NICU on the development of circadian rhythms in preterm infants. Semin Perinatol 2000;24(4):247-57.

43. McGraw K, Hoffmann R, Harker C, Herman JH. The development of circadian rhythms in a human infant. Sleep 1999;22(3):303-10.

44. FigueiroMG,Appleman K, BulloughJD, Rea MS. discussion of recommended standards for lighting in the newborn intensive care unit. J Perinatol 2006;26:S19-26.

45. Mann NP, Haddow R, Stokes L, Goodley S, Rutter N. Effect of night and day on preterm infants in a newborn nursery: randomised trial. Br Med J (Clin Res Ed) 1986;293(6557): 1265-7.

46. MillerCL, White R, Whitman TL, O'Callaghan MF, Maxwell SE. The effects of cycled verses noncycled lighting on growth and development in preterm infants. Infant Behav Dev 1995;18(1):87-95.

47. Brandon DH,Holditch-Davis D, Belyea M. Preterm infants born at less than 31 weeks' gestation have improved growth in cycled light compared with continuous near darkness. J Pediatr 2002;140(2):192-9.

48. Jung IS. Effects of cycled lighting on body weight, physiological variables and behavioral states in low birth weight infants. Taehan Kanho Hakhoe Chi 2005;35(1):143-53.

49. Begum E, Bonno M, Obata M, Yamamoto H, et al.Emergence of physiological rhythmicity in term and preterm neonates in a neonatal intensive care unit. J Circadian Rhythms 2006;4(1):11.

50. Morag I, Ohlsson A. Cycled light in the intensive care unit for preterm and low birth weight infants. Cochrane Database Syst Rev 2011;(1):CD006982.

51. García del Río M, Sánchez Luna M, Doménech Martínez E, Izquierdo Macián I, et al. Revisión de los estándares y recomendaciones para el diseño de una unidad de neonatología. An Pediat (Barc) 2007;67(6):594-602.

52. Hellstrom-Westas L, Inghammar M, Isaksson $\mathrm{K}$, Rosen I, Stjernqvist K. Short-term effects of incubators covers on quiet sleep in stable premature infants. Acta Paediatr 2001;90(9):1004-8.

53. Ríos GM. Síndrome ictérico del primer trimestre. Rev Chil Pediatr 2002;73(4):399-401.
54. Martínez JC. El real problema del recién nacido ictérico. Nuevas guías dela Academia Estadounidense de Pediatría. Arch Argent Pediatr 2005;103(6):524-32

55. Rea MS, ed. IESNA Lighting Handbook. 9th ed. New York: Illuminating Engineering Society of North America; 2000.

56. Fulton A, Abramov I, Allen J, Gwiazda J, et al. Optical radiation effects on visual development. En Waxier $\mathrm{M}$, Hitchins VM, eds. Optical Radiation and Visual Health. Boca Raton, Fla: CRC Press, Inc.; 1986:137-46.

57. Ham WT, Mueller HA, Sliney DH. Retinal sensitivity to damage from short wavelength light. Nature 1976;260(5547):153-5.

58. Van Norren D, Schellekens P. Blue light hazard in rat. Vision Res 1990;30(10):1517-20.

59. Sperling HG. Prolonged intense spectral light effects on rhesus retina. In Williams TP, Baker BN, eds. The Effects of Constant Light on Visual Processes. Nueva York: Plenum Press; 1980.Págs.195-214.

60. Gies HP, Roy CR. Bilirubin phototherapy and potential UVR hazards. Health Phys 1990;58(3):313-20.

61. Terry TL. Extreme prematurity and fibroblastic overgrowth of persistent vascular sheath behind each crystalline lens. Am J Ophthalmol 1942;25(2):203-4.

62. Campbell K. Intensive oxygen therapy as a possible cause of retrolental fibroplasias: a clinical approach. Med J Aust 1951;2(2):48-50.

63. Kuwabara T, Funahashi M. Light damage in the developing rat retina. Arch Ophthalmol 1976;94(8):1369-74.

64. Messner KH, Maisels MJ, Leure-DuPree AE. Phototoxicity to the newborn primate retina. Invest Ophthalmol Vis Sci 1978;17(2):178-82.

65. Glass P, Avery GB, Subramanian KNS, Keys MP, et al. Effect of bright light in the hospital nursery on the incidence of retinopathy of prematurity. N Engl J Med 1985;313(7): 401-4.

66. Reynolds JD, Hardy RJ, Kennedy KA, Spencer R, et al Lack of efficacy of light reduction in preventing retinopathy of prematurity. Light reduction in retinopathy of prematury (LIGHT-ROP) Cooperative Group. $N$ Engl J Med 1998;338(22):1572-6.

67. Landry RJ, Scheidt PC, Hammond RW. Ambient Ligth and Photothepary Conditions of Eigth Neonatal Care Units: a summary report. Pediatrics 1985;75(2 Pt 2):434-6.

68. Phelps DL, Watts JL. Early light reduction for preventing retinopathy of prematurity in very low birth weight infants. Cochrane Database Syst Rev 2001;1:D000122.

69. Antonucci R, Porcella A, Fanos V. The infant incubator in the neonatal intensive care unit: unresolved issues and future developments. J Perinat Med 2009;37(6):587-98. 


\section{ANNEX}

\section{Methodology}

A background search was conducted, comprising applicable Argentine laws (mandatory) and regulations (optional), international acts and standards, professional association guidelines, postgraduate theses, technical and academic reports, and peer-reviewed scientific articles. The search engine was Google Scholar, and the following key words and their combinations (in English) were used: NICU, hospital, healthcare, lighting, natural light, developmental care, environmental factors, human factors, environmental neonatology, standards, guidelines, checklist, design, preterm, jaundice, blue light hazard. And, in Spanish: UCIN, hospital, iluminación, luz natural, cuidado centrado en el desarrollo, maternidad centrada en la familia, neonatología ambiental, estándares, guías, lista de chequeo, diseño, prematuros, ictericia neonatal. A time filter was applied for the search of bibliography published between 1990 and 2015. An initial search and the critical review of documents resulted in the identification of key authors and publications; papers prior to the selected period were included in the reference material based on their relevance in terms of originality and impact. As a result, 70 technical and scientific documents were added to the corpus, serving as the basis of this update. 